\title{
A Novel Scheduled Power Management using Iot Controlled Energy Meter
}

\author{
C. Pavithra, Y. Pavithra, R. Geethamani, V. Sankari
}

\begin{abstract}
In this proposed system, scheduled power management is to reduce the excess use of energy and to reduce the energy tariff of the domestic consumers. The price differs, if one unit exceeds the value fixed by tariff 1a plan. For domestic customers, scheduling of energy is done by using energy meter which is controlled by IOT and Arduinos. If the consumer uses excess of scheduled energy the user gets an SMS and the circuit will be tripped automatically, in case if there is necessity for more energy, we switch to normal function from the scheduled function which can be maintained by IoT. The consumer can check the energy consumption in webpage. The internet of things paradigm has been proposed in order to check the energy consumption and also for automation purposes like tripping the circuits when energy usage is increased. A very low cost, advanced embedded hardware has been used to make the prototype model.
\end{abstract}

Keywords- IOT (internet of things), tariff, scheduled energy, Arduino.

\section{INTRODUCTION}

Development of a country depends on the electricity generation and its utilization. Electrical energy is used in the almost all sectors like industry, transport, communication, agriculture, households etc. The energy demand is keeps on increasing with increase in the growth of the country. So, it become complex to meet the demand of the consumer.

In order to match the demand and generation also to reduce the excessive use of electrical energy the proposed system make use of technology to connect the energy meter with the IOT, which aims at the cut down of bill amount also reduce the excessive use of electrical energy.

\section{LITRERATURE SURVEY}

It became challenging task for the distribution companies to track the peak demand of the consumers, so consumers are in the need to pay the excessive amount for peak energy consumption. It is important to track the maximum demand of the load regularly. In the scheduled power management maximum peak detection is essential.

Revised Manuscript Received on December 30, 2019.

* Correspondence Author

C. Pavithra, Assistant Professor, Department of EEE, Sri Krishna College of Engineering and Technology, Coimbatore (Tamil Nadu) India. E-mail Id: pavithra@skcet.ac.in

Y. Pavithra, PG Scholar, Department of EEE, Sri Krishna College of Engineering and Technology, Coimbatore (Tamil Nadu) India. E-mail Id: 18eppe001@skcet.ac.in

R. Geethamani, Assistant Professor, Department of EEE, Sri Krishna College of Engineering and Technology, Coimbatore (Tamil Nadu) India. E-mail Id: geethamai@skcet.ac.in

V. Sankari, PG Scholar, Department of EEE, Sri Krishna College of Engineering and Technology, Coimbatore (Tamil Nadu) India. E-mail Id: 18eppe002@skcet.ac.in

(C) The Authors. Published by Blue Eyes Intelligence Engineering and Sciences Publication (BEIESP). This is an open access article under the CC BY-NC-ND license (http://creativecommons.org/licenses/by-nc-nd/4.0/)
The scheduled power management is to reduce the excess use of energy and to reduce the energy tariff of the domestic consumers. The price differs when the energy usage exceeds the value fixed by the plan developed by the government. When the energy usage exceeds, the cost to be paid by the consumers also increases. IOT plays an important role in real time applications. Here IOT paradigm has been used in order to check the energy consumption and also for automation purposes.In homes, by using many electrical appliances, consumption of electrical energy is more or beyond the limit for budget class families. The electricity budget for these families will be too high. So to overcome the electricity budget problem for these families, the scheduled energy pattern can be followed. In day-to-day life, none of the consumers are interested to see the energy consumption in the energy meter reading in their homes. So, to notify the consumers about their energy consumption, energy consumption notification is sent through their mobile SMS in particular period of consumption.

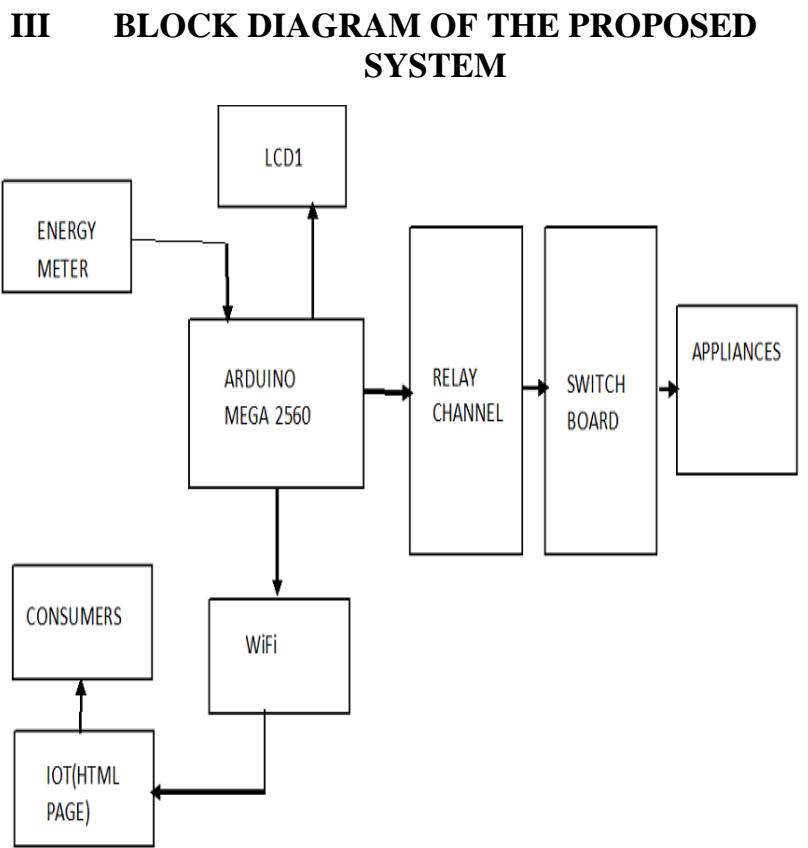

Fig 1: Scheduled Power Management using IoT Controlled Energy Meter

\section{HARDWARE DESCRIPTION}

\section{A. Arduino Mega}

Arduino Mega is a 54 digital pin microcontroller which has analog inputs ports, crystal oscillator, a Universal serial board etc, the analog signals are converted into digital based on the required data input

\section{Published By:}




\section{B. Wi-Fi (ESP8266):}

The ESP8266 is a SOC which is self-contained with inbuiltTCP/IP P-Stack protocol that can access the Wi-Fi module.Each ESP8266 module comes pre-programmed.

The ESP8266 module is an extremely cost effective and user friendly.

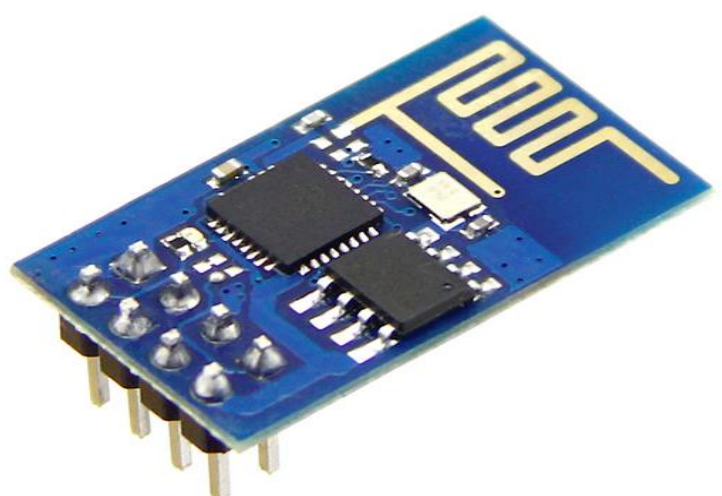

Fig 2: Wi-Fi (ESP8266)

\section{IOT (internet of things):}

A number of information or data can be viewed or retrieved using the internet either in mobile or personal computers from the place of data upload. The device is monitored using the IoT platform control. The proposed system avoids the physical work of human being to take the reading instead arduino unit will keep track of the energy meter reading in and can be sent to the cloud which can be displayed on the webpage so the customer can see their electricity bill at anytime from anywhere.

When the loads are connected, the energy meter gives the reading of amount of power consumed in the LCD display, LED in the energy meter will blink continuously will read the power consumption. In the proposed system the arduino based microcontroller will monitor the energy meter reading and the cost of the EB bill is calculated continually. When the actual reading of the household is near the preset threshold value, notification will create the awareness. As per the consumers need there is the possibility to change the threshold value. A notification information is sent to the consumers in case if the consumer value is near or above the preset threshold value. When the consumers reading will be near about to the set threshold value it will send a notification value to the consumer and circuit get disconnected from the line, get tripped off automatically. We can turn ON the circuit only by changing the threshold value.

\section{HTML (Web page):}

HTML (Hypertext markup language) that can be accessible through the internet or it can be accessed through other networks. This webpage can be accessed by entering a URL address and this web page also contains text, graphics, and hyperlinks to other webpages and files. For viewing a webpage we need browser like internet explorer, edge, firefox, chrome. We can open a webpage by entering the URL. The data like power and energy units are periodically updated in the webpage

\section{E. Energy Meter}

Energy meter measures the amount of energy consumed by the consumers based on the load connected to it. It senses the voltage and current used by the line inturn gives the energy reading. The energy parameters are continually sent to the aurdino which compare the actual energy consumed with the energy reference which is a preset value. The data are continuously sent to the cloud. The measure value also displayed in the LCD screen.

\section{F. Working Of The Proposed System}

In normal operation, the supply will pass through the energy meter and to switch board and to electrical appliances. In this project, first the supply will pass through the energy meter. There is an LED light that blinks according to the energy usage. Then tapping the blinking LED using the Arduino (Microcontroller) to count the number of pulses (blink). The next part is the relay board, which is directly connected between the energy meter and the switch board in NC position. When scheduled plan is needed, the supply from the energy meter to switch board through the relay board in NC position is cut-off by the Arduino (Microcontroller) and the control to switch board is taken over by the Arduino through the relay channel. During the scheduled plan, appliances are powered up by the Arduino according to the need of usage which is already preset.

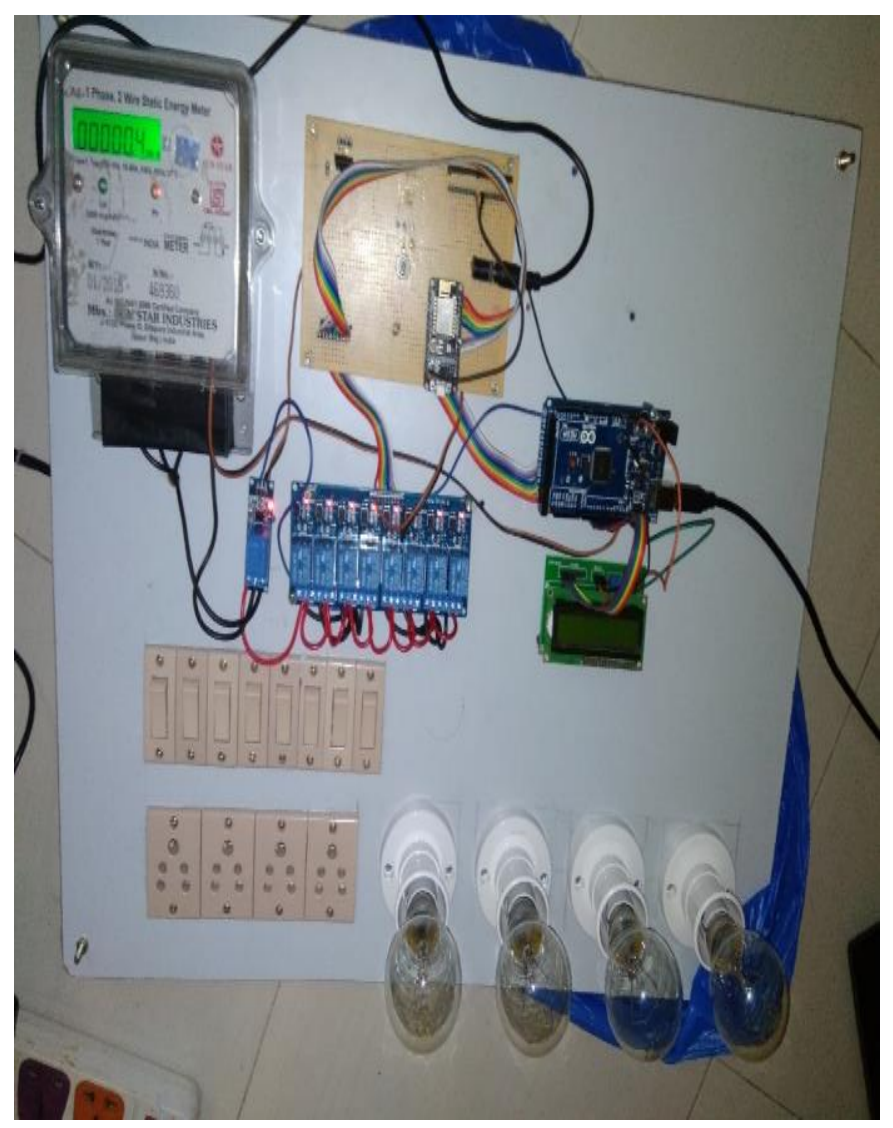

Fig 4: Hardware implementation of the proposed system

The LCD connected with the Arduino (Microcontroller) will display the energy usage in Wh (watt hr) and the net billing amount. The Wi-Fi module will update the energy to the cloud, so that the energy consumption can be checked and the scheduled plan can be switched by controlling the relay board through the internet.

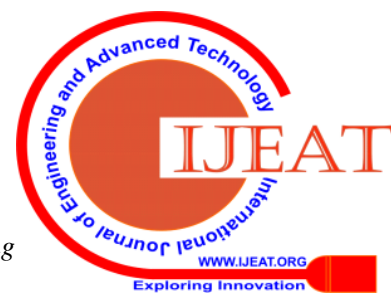




\section{RESULT}

Table 1: Comparision of results of proposed and existing system

\begin{tabular}{|l|l|l|l|l|}
\hline & $\begin{array}{l}\text { Scheduli } \\
\text { Engrgy }\end{array}$ & Billing & $\begin{array}{l}\text { Tripper } \\
\text { ON if } \\
\text { excess } \\
\text { energy } \\
\text { consumpti } \\
\text { on }\end{array}$ & $\begin{array}{l}\text { Webpa } \\
\text { ge } \\
\text { Display }\end{array}$ \\
\hline $\begin{array}{l}\text { Existin } \\
\text { g } \\
\text { System }\end{array}$ & $\begin{array}{l}\text { Not } \\
\text { Possible }\end{array}$ & $\begin{array}{l}\text { Billed in } \\
\text { Excess } \\
\text { amount }\end{array}$ & No & $\begin{array}{l}\text { Not } \\
\text { availabl } \\
\text { e }\end{array}$ \\
\hline $\begin{array}{l}\text { Propose } \\
\text { d }\end{array}$ & Possible & $\begin{array}{l}\text { Predefin } \\
\text { ed } \\
\text { amount } \\
\text { in the } \\
\text { bill }\end{array}$ & Yes & $\begin{array}{l}\text { Availabl } \\
\text { e with } \\
\text { prompt } \\
\text { updatio } \\
\text { n in the } \\
\text { data }\end{array}$ \\
\hline
\end{tabular}

The above tabulation shows the proposed scheduled power management using arduino controller is prominently provide controlled use of power and the bill amount is reduced. IoT based controller send the amount of energy usage by consumed by the consumers.

\section{CONCLUSION}

Scheduled monitoring of energy using an IoT is a useful innovative application of internet of things for scheduled usage of energy to limit the electricity bill and it will help the consumer to avoid the excess use of electricity. In this proposed system the user can periodically monitor the energy consumed which make user to easily pay the electricity bill, the system will send the message to the consumer periodically. Based on this IoT we can predict the future energy demands.

\section{REFERENCES}

1. Sudhish N George and Ashna K, "GSM based automatic energy meter reading system with instant billing", IEEE publications for International Multi-Conference on Automation, Computing, Communication, Control and Compressed Sensing (iMac4s), 2013 ,March 2013, pp. 65-71.

2. Md. MejbaulHaque "Microcontroller Based Single Phase Digital Prepaid Energy Meter for Improved Metering” International Journal of Power Electronics and Drive System (IJPEDS) December 2011, pp. 139 147

3. Ling Zou, Sihong Chu and Biao Guo., "The Design of Prepayment Polyphase Smart Electricity Meter System," International Conference on Intelligent Computing and Integrated Systems (ICISS), pp. 430-432, 22-24, Dec 2010

4. B.S.Koay,S.S.Cheah, Y.H.Sng, P.H.J.Chong,andH.W.Kuek, "Design and Implementation of bluetooth energy meter" IEEE 2003

5. Loss,Petal., "A Single Phase Microcontroller Based Energy Meter," IEEE Instrumentation and Measurement Technology Conference. St. Paul Minnesoa, USA, May 18-21, 1998

6. K. S. K. Weranga et al., "Smart Metering for Next Generation Energy Efficiency \& Conservation”, IEEE PES ISGT Asia 2012, pp. $1-8$

7. R. Dhananjayan , E. Shanthi," Smart Energy Meter with Instant Billing and Payment" Vol.2,Special Issue 1,March 2014

8. K. S. K. Weranga et al., "Smart Metering for Next Generation Energy Efficiency \& Conservation”, IEEE PES ISGT Asia 2012, pp. $1-8$

9. $\quad$ Ling Zou, Sihong Chu and Biao Guo.,"The Design of Prepayment Polyphase Smart Electricity Meter System," International
Conference on Intelligent Computing and Integrated Systems (ICISS), pp. 430-432, 22-24, Dec 2010

\section{AUTHORS PROFILE}

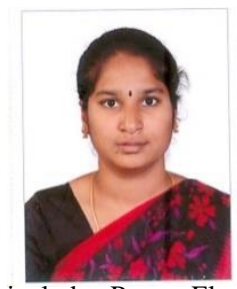

C. Pavithra Completed her M.E in Electrical Drives and embedded Control from Anna University of Technology Coimbatore in the year 2012, and B.E EEE from sri Krishna college of Engineering \& Technology Coimbatore in the year 2010.She is currently working as Assistant Professor in Sri Krishna college of Engineering and Technology Coimbatore. Her area of interest includes Power Electronics, Renewable Energy System, Electrical Drives. She is having more than 6 paper publication in Scopus indexed journal.

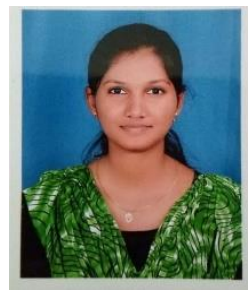

Y. Pavithra completed her B.E. degree in Electrical and Electronics Engineering from P.A. College of Engineering and Technology, Pollachi, India in 2014 and Pursuing M.E degree in Power Electronics and Drives in Sri Krishna College of Engineering and Technology, Coimbatore, India. Her research interests include multilevel power converters, pulse width modulation techniques, and wind power integration.

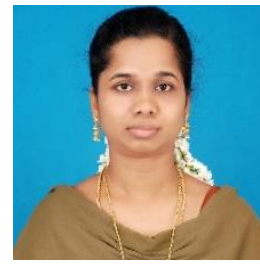

R. Geethamani completed her under graduation in B.E (EEE) from Shanmugha College of Engineering, Tanjore in the year of 2001. She obtained her M.E (Applied Electronics) from Thanthai Periyar Govt. Institute of Technology, Vellore in the year of 2008. She is currently working as Associate Professor in the department of EEE, Sri Krishna College of Engineering and Technology, Coimbatore-641008. Her research interests are Embedded systems, RES, Soft Computing and Intelligent Controllers.

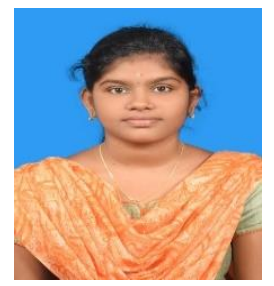

V. Sankari completed her B.E. degree in Electrical and Electronics Engineering from P.S.N.A. College of Engineering and Technology, Dindugal, India in 2014 and Pursuing M.E degree in Power Electronics and Drives in Sri Krishna College of Engineering and Technology, Coimbatore, India. Her research interests include multilevel power converters, pulse width 